Cultures \& Conflits

54 | été 2004

Approches critiques de la sécurité

\title{
Une collaboration franco-canadienne
}

\section{Comité éditorial}

\section{(2) OpenEdition}

Journals

\section{Édition électronique}

URL : http://journals.openedition.org/conflits/1522

DOI : 10.4000/conflits.1522

ISSN : $1777-5345$

Éditeur :

CCLS - Centre d'études sur les conflits lilberté et sécurité, L'Harmattan

\section{Édition imprimée}

Date de publication : 1 juin 2004

Pagination : 5-7

ISBN : 2-7475-7301-X

ISSN : 1157-996X

Référence électronique

Comité éditorial, « Une collaboration franco-canadienne », Cultures \& Conflits [En ligne], 54 | été 2004, mis en ligne le 08 janvier 2010, consulté le 30 mars 2021. URL : http://journals.openedition.org/ conflits/1522; DOl : https://doi.org/10.4000/conflits.1522

Ce document a été généré automatiquement le 30 mars 2021.

Creative Commons License 


\title{
Une collaboration franco- canadienne
}

\author{
Comité éditorial
}

1 Ce numéro présente les recherches trop souvent méconnues de nos amis canadiens. Il est le second volet d'une série de publications qui rendent compte d'un dialogue sur l'étude des questions de sécurité qui se poursuit depuis plusieurs années entre côté français notre revue, le CERI, l'université de Paris X Nanterre et côté canadien l'université de Toronto, l'université de Montréal, l'UQAM (université du Québec à Montréal) et tout particulièrement l'équipe d'Alex Macleod.

2 Le premier volet avait été la publication d'un ouvrage intitulé Vers des périmètres de sécurité? La gestion des espaces continentaux en Amérique du Nord et en Europe, édité par Stéphane Roussel, Michel Fortmann et Alex Macleod, aux éditions Athéna en 2003¹. Cet ouvrage faisait suite au colloque organisé au CERI les 10 et 11 Septembre 2001 dont le titre résonna avec l'actualité de ce jour tragique : «L'Etat gère-t-il toujours la sécurité ?». Il développait la réflexion sur la gestion des frontières, l'extension de la notion de protection des frontières et de sécurité intérieure aux Etats-Unis et son impact sur ses voisins immédiats et sur l'Europe. Il présentait aussi une réflexion de l'équipe française sur la notion de champ de l'(in)sécurité et sur la gestion des frontières.

3 Un troisième volet reprendra très prochainement la problématique de l'équipe française sur ces points et sur la nord-irlandisation du monde ${ }^{2}$ qui est le résultat de la politique de Georges Bush et de son choix de la voie militaire dans la lutte antiterroriste $^{3}$. Mais il nous semblait important de développer auparavant une discussion sur les enjeux méthodologiques et épistémologiques des questions de sécurité et d'aborder la diversité interne aux approches dites constructivistes et critiques sans les rapporter à leurs opposants cynico-réalistes ou aux seuls débats sur la puissance et la sécurité vu pour et par les Etats-Unis.

4 Comme le montre très bien l'article d'Alex Macleod, le champ des études de sécurité est à l'image de la discipline des Relations Internationales de manière générale : elle se décline en une multiplicité d'approches, de sensibilités et de postures. En effet, les 
études de sécurité, dès lors qu'elles ne communient plus dans les présupposés communs de stratégistes de la Guerre Froide, ont aujourd'hui tendance à se diversifier en courants sous-tendues par des hypothèses et des partis pris différents, ainsi que par des positionnements plus structurels liés aux positions de pouvoir au sein du champ académique et à la localisation institutionnelle et géographique des chercheurs.

Plutôt que d'y voir une quelconque segmentation de la recherche ou un éloignement des préoccupations "centrales", c'est-à-dire de celles répondant aux intérêts des acteurs dominants des pays dominants de la scène des Relations Internationales, nous voyons au contraire dans cette diversité une formidable opportunité de renouvellement et de reformulation des questions d' (in)sécurité. Dans ce contexte, il est par conséquent important de nourrir le débat international afin que l'on ne perde pas de vue ce qui rapproche et distingue ces perspectives, et plus généralement ce qui permet de faire avancer la réflexion théorique et donc aussi la recherche empirique. Cette démarche s'inscrit ainsi dans l'esprit de cette revue qui est aussi d'ouvrir les recherches en cours sur des perspectives variées et/ou nouvelles et de nouer des liens et des débats par-delà les frontières pré-établies ou imposées.

Dans une communication très remarquée, lors de la dernière Convention annuelle de L'International Studies Association à Montréal en mars 2004, Ole Wæver a proposé une analyse de l'émergence et de la constitution de théories européennes sur les études de sécurité en montrant comment celles-ci étaient largement associées à des lieux de production intellectuelle spécifiques comme Aberystwyth, Paris et Copenhague ${ }^{4}$. Il nous a semblé important de présenter à un public francophone ce qui s'écrit et se pense au Canada - et plus particulièrement au Québec - et cela d'autant plus que si nombre des contributions de ce numéro se positionnent par rapport à ces «écoles européennes » évoquées par Wæver, elles s'inscrivent également dans le cadre d'un débat nord-américain et cela notamment dans leur présentation du « constructivisme dominant ».

7 Cela ne revient pas à dire que ce numéro relèverait forcément d'une approche parfaitement homogène qui serait commune aux différentes contributions qui y sont présentées. Cependant, il nous semble qu'elles se singularisent assez dans le débat international en cours pour que l'on puisse ici parler d'une approche canadienne. A ce titre, on peut noter que tout en partageant avec le projet de la sociologie politique internationale - qui sous-tend un certain nombre d'articles de cette revue - un certain nombre de postulats et de postures critiques, il s'en démarque aussi par bien des aspects.

8 Nous espérons ainsi avec ce dossier initier un certain nombre de numéros qui à travers des focales différentes aborderons la thématique générale des enjeux de sécurité tout en l'inscrivant dans un dialogue international qui en dehors du cadre d'un certain nombre de conférences, de colloques et de rencontres internationales, fait parfois cruellement défaut. 


\section{NOTES}

1. Fortmann M., MacLeod A. et Roussel S. (dir.), Vers des périmètres de sécurité? La gestion des espaces continentaux en Amérique du Nord et en Europe, Montréal, CEPES/Athéna Editions, 2003.

2. Cultures\&Conflits $n^{\circ} 56$, à paraître.

3. Voir notre précédent numéro intitulé « Défense et identités. Un contexte sécuritaire global ? ", Cultures\&Conflits, $\mathrm{n}^{\circ} 44$, hiver 2001.

4. Wæver Ole, «Aberystwyth, Paris, Copenhagen - New 'Schools' in Security Theory and their Origins between Core and Periphery, communication présentée dans le cadre du panel Geocultural Epistemologies in IR: Thinking Security Differently, 45eme Convention Annuelle de l'ISA, International Studies Association, Montréal, mars 2004. Disponible en version PDF sur le site de l'ISA : http://www.isanet.org/ 